\title{
Pattern and predictors of mortality in sandstone quarry workers
}

\begin{abstract}
Study of silicosis was conducted in 1992-1994, which included a sample of 458 sandstone quarry workers of Jodhpur. To find out the pattern and predictors of mortality among sandstone quarry workers. Houses of all workers were visited and the worker's status was recorded. Standardized mortality ratio (for all causes of death) was calculated. Cox proportional hazard model was applied to study the association of different variables with mortality. Total $97.8 \%$ workers could be followed, of whom, $10.9 \%$ had died $(S M R=1.72 ; 95 \% \mathrm{Cl} 1.23-2.19)$. The average age at the time of death of the deceased was $51.8 \pm$ 12.5 years. Mortality was higher among silicotics $(\mathrm{SMR}=$ $2.54 ; 95 \% \mathrm{Cl} 1.43-3.66)$, smokers $(\mathrm{SMR}=1.83 ; 95 \% \mathrm{Cl}$ $1.27-2.39$ ), and those showing mixed abnormality in pulmonary function test $(\mathrm{SMR}=2.73 ; 95 \% \mathrm{Cl} 1.24-4.21$ ). In multivariate Cox proportional hazard model, restriction in spirometery ( $\mathrm{HR}=13.95 ; 95 \% \mathrm{Cl} 9.14-21.29)$, longer duration (> 15 years) of working in quarries $(\mathrm{HR}=7.29$; $95 \% \mathrm{Cl} 5.19-10.24)$, chronic dyspnoea ( $\mathrm{HR}=6.48 ; 95 \%$ Cl $4.70-8.95)$, silicosis ( $\mathrm{HR}=6.03 ; 95 \% \mathrm{Cl} 4.85-7.51)$, $\mathrm{BMI}<1.75(\mathrm{HR}=3.50 ; 95 \% \mathrm{Cl} 2.78-4.41)$, and chronic chest pain ( $\mathrm{HR}=3.28 ; 95 \% \mathrm{Cl} 2.51-4.28)$ emerged as significant predictors of all cause mortality.

It can be concluded that sandstone quarry workers died at a younger age. In absence of certified cause of death, these predictors suggest that silicosis, COPD, lung cancer, and tuberculosis might be underlying causes of higher mortality. This study underlines the need for adopting measures among workers for the prevention from exposure to fine dust.
\end{abstract}

Key words: Mortality, Predictors, Stone quarry workers

\section{INTRODUCTION}

Approximately 50000 workers are engaged in about 15000 sandstone quarries in Jodhpur district of Rajasthan (India). It is an unorganized sector and record of their employment history, working hours, environmental conditions, accidents, sickness, or deaths are not maintained. Registration of all deaths is mandatory in India but from the records of death registration, it is not possible to separate out sandstone quarry workers from all deceased. Death certificates or certified cause of death are normally not available. Cases of compensation for occupational diseases, accidents, or deaths are not commonly filed. Pattern of morbidity and mortality in these workers can therefore not be studied from records. A prospective study was therefore carried out to explore the mortality pattern in sandstone quarry workers. In 1992-1994, we had carried out an epidemiological study of silicosis in sandstone quarry workers of Jodhpur district, ${ }_{1}^{[1]}$ which included a sample of 458 workers. In order to study the pattern and predictors of mortality, experienced by sandstone quarry workers, a rapid follow up of these 458 workers was carried out, and the results are presented.

\section{MATERIALS AND METHODS}

In the epidemiological study of silicosis in Jodhpur district carried out by us in1992-1994, the sample included 416 active workers and $42 \mathrm{ex}$ workers selected by systematic random sampling of quarries. A rapid follow up of these workers was carried out in August 2002. All 416 active workers were included in the followup study. Most workers were likely to discontinue their job some time before their death, which are likely to be excluded from the follow-up study if only active workers are included in follow up. To avoid influence of such 'healthy worker effect' in the results of the follow-up study, 42 ex-workers, who had worked in sandstone quarries and had discontinued the work by 1993-1994, because of sickness, disability, or old age who were included in the earlier study,
M. L. Mathur Desert Medicine Research Centre, Jodhpur, India

For correspondence: Dr. M. L. Mathur Deputy Director, Desert Medicine Research Centre, New Pali Road, Jodhpur - 342005, India. E-mail: mmmurli@rediffmail.com

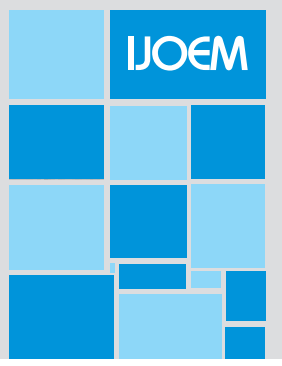


were also included in the follow up. Thus all 458 workers were followed up in August 2002. Houses of all 458 workers were visited by an investigator and the worker's status as (i) still working, (ii) discontinued job but alive or (iii) died was recorded. The information was obtained from an available adult member of his household. All those who died through July 2002 were recorded as deceased. The month and year of their death and their disease at time of death as reported by their relatives were recorded.

\section{Characteristics of sample population in 1992-1994}

At the time of registration, the worker's exact age in completed years, clinical findings and detailed occupational history was recorded. Spirometery of these subjects was carried out using computerized spirometer (Autospirror). Their X-ray chest was taken at $300 \mathrm{~mA}$ and was read as per International classification of radiographs of pneumoconiosis provided by International Labor Organization. ${ }^{[2]}$ Opacities suggestive of silicosis were found in radiographs of $12.4 \%$ workers, signs of present or past lesions of tuberculosis were found in 18.1\% radiographs and sputum of $3.6 \%$ workers was positive for Acid Fast Bacilli by smear examination or culture. At time of registration in 1992-1994, their mean age was $33.7 \pm 11.8$ years and mean duration of working in sandstone quarries was $13.8 \pm 8.4$ years [Table 1]. Average concentration of respirable dust in the quarries was $46.9 \pm 15.99 \mathrm{mg} / \mathrm{m}^{3}$ air; the stone dust had 46.49-64.69\% quartz. For each lung function variable the individual's best value was defined as the highest of the three readings. For each individual predicted forced vital capacity (FVC), peak expiratory flow rate, and FEV, were calculated using standard reference prediction equations published by Purohit et al. ${ }^{[3]}$ for the healthy subjects of Rajasthan. Restriction was defined as FVC less than $80 \%$ of predicted FVC. Obstruction was defined as FEV1 less than $75 \%$ of his own FVC. Obstruction without restriction was observed in $36.0 \%$, restriction without obstruction was observed in $10.5 \%$, both obstruction and restriction were observed in 14.7 and $38.8 \%$ workers had normal pulmonary function test (PFT). The height was measured with an anthropometer while the subject stood erect on a flat platform looking straight, in a forward direction. Body weight was measured with light clothing, without shoes using a bathroom scale. BMI was calculated as [weight in $\mathrm{gm} /(\text { height in } \mathrm{cm})^{2}$ ]. BMI was 1.75 or less in $40.5 \%$ workers, whereas it was above 1.75 in 59.5\% workers. Personal history about use of alcohol or opium was also obtained. Prevalence of alcohol use was $61.1 \%$, while $3.5 \%$ were ex-users, and only $20.3 \%$ workers used alcohol for more than 15 days/month. Use of crude opium with social sanction is common in adult males of this region. While 21.4\% workers consumed opium, 9.8\% were addicts of opium. The smoking status was recorded as smoker or nonsmoker; ex-smokers were taken as smokers. Majority (81.9\%) of workers were smokers.

\section{Statistical analysis}

Findings of follow-up study were added to data of 1992-1994 entered in software D-base III. Age and sex-specific death rates of rural population of India were obtained from the sample registration system (SRS), Registrar General, India. ${ }^{[4]}$ Standardized mortality ratio (for all causes of death) and its 95\% confidence intervals (CI) were calculated as per standard procedure. ${ }^{[5]}$ Software EPI Info 2002 was used and Cox proportional hazard model was applied to study the associations of BMI, result of PFT, opacities suggestive of silicosis in X-ray, TB in X-ray, duration of working in sandstone

Table 1: Baseline data for sandstone quarry workers at time of registration in 1992-1994

\begin{tabular}{|c|c|c|c|}
\hline & $\begin{array}{l}\text { Workers working at } \\
\text { time of registration }\end{array}$ & $\begin{array}{l}\text { Workers who had discontinued } \\
\text { work at time of registration }\end{array}$ & Total \\
\hline Number registered in 1992-1994 & 416 & 42 & 458 \\
\hline Average age at time of registration (years) & $31.9 \pm 10.3$ & $51.1 \pm 11.5$ & $33.7 \pm 11.8$ \\
\hline Range & $11-65$ & $25-70$ & $11-70$ \\
\hline Average duration of working in sandstone quarries (years) & $12.9 \pm 7.8$ & $22.2 \pm 9.9$ & $13.8 \pm 8.4$ \\
\hline Range & $1-40$ & $6-50$ & $1-50$ \\
\hline Average BMI & $1.80 \pm 0.20$ & $1.75 \pm 0.27$ & $1.79 \pm 0.20$ \\
\hline $\mathrm{BMI}>1.75$ & $60.4 \%$ & $42.9 \%$ & $59.5 \%$ \\
\hline \multicolumn{4}{|l|}{ Result of PFT } \\
\hline Normal PFT (N) & $41.0 \%$ & $11.6 \%$ & $38.8 \%$ \\
\hline Restriction without obstruction (R) & $10.7 \%$ & $7.7 \%$ & $10.5 \%$ \\
\hline Obstruction without restriction $(0)$ & $34.6 \%$ & $53.8 \%$ & $36.0 \%$ \\
\hline Mixed $(R+0)$ & $13.7 \%$ & $26.9 \%$ & $14.7 \%$ \\
\hline Opacities suggestive of silicosis in X-ray chest & $9.9 \%$ & $38.1 \%$ & $12.4 \%$ \\
\hline Opacities suggestive of TB in X-ray chest & $15.6 \%$ & $42.9 \%$ & $18.1 \%$ \\
\hline Smokers & $82.2 \%$ & $78.6 \%$ & $81.9 \%$ \\
\hline Alcohol consumption (> 15 days/month) & $21.4 \%$ & $9.5 \%$ & $20.3 \%$ \\
\hline Opium consumers & $20.0 \%$ & $35.7 \%$ & $21.4 \%$ \\
\hline Opium addicts & $8.2 \%$ & $26.2 \%$ & $9.8 \%$ \\
\hline Ch. dyspnoea & $41.1 \%$ & $76.2 \%$ & $44.3 \%$ \\
\hline Ch. pain chest & $49.3 \%$ & $64.3 \%$ & $50.7 \%$ \\
\hline $\mathrm{C} / 0$ hemoptysis in last 6 months & $24.8 \%$ & $45.2 \%$ & $26.6 \%$ \\
\hline
\end{tabular}


quarries, opium addiction, smoking habit, alcohol consumption, complain of hemoptysis in last 6 months, complain of chronic pain chest and complain of chronic dyspnoea with mortality. In this univariate analysis, hazard ratios were adjusted for age. The variables that emerged as significant predictors of all cause mortality in univariate analysis were then tested in multivariate Cox proportional hazard model adjusted for age.

\section{RESULTS}

All 458 workers were males. Female workers were not included in the study as very few females worked in sandstone quarries. Out of 458 male workers registered, 448 (97.8\%) could be followed, while ten were lost to follow up. Sixty-five (14.5\%) workers had discontinued job because of their sickness. Three hundred and thirty-four (74.5\%) workers were still working in sandstone quarries in August 2002. Forty-nine (10.9\%) workers had died by July 2002 [Table 2]. Compared to the reference population, mortality from all causes experienced by sandstone quarry workers was significantly higher than expected (SMR $=1.72,95 \%$ CI $1.23-2.19$ ). The average age at time of death of those who died was $51.8 \pm$ 12.5 years [Table 2]. One deceased had died in a road traffic accident, exact cause of death of other deceased could not be found out, as no records of their treatment were available. But all the deceased were suffering from chronic cough (chronic respiratory disease) at the time of death as per the history given by their relatives. Out of 416 workers who were actively working at time of registration, 28 died during the follow-up period, and their average age at time of death was $46.0 \pm 10.6$ years. The workers who had opacities suggestive of silicosis in their chest X-ray at the time of registration, experienced significantly higher mortality (SMR $=2.54,95 \%$ CI 1.43 - 3.66), whereas SMR for those who did not exhibit opacities suggestive of silicosis in their radiographs at time of registration was 1.31 (95\% CI $0.833-1.79$ ). Prevalence of obstruction, restriction, and mixed lesions in spirometery were not significantly different in smokers and nonsmokers at the time of registration. Smokers experienced higher mortality (SMR $=1.83 ; 95 \%$ CI $1.27-2.39$ ). The SMR, among nonsmokers was 1.30 ( $95 \%$ CI $0.40-2.20$ ). Table 3 shows SMR of workers according to result of lung function test at time of registration. The SMR among those who showed only obstruction in spirometery was 1.32 (95\% CI $0.63-2.02)$, while it was 2.34 (95\% CI $0.29-4.39)$ in those with only restriction and it was 0.54 (95\% CI -0.07-1.61) in those with normal lung function. Significantly, higher mortality was experienced by the workers, who exhibited obstruction, as well as restriction on spirometery (SMR $=2.73,95 \%$ CI $1.24-4.21$ ).

Table 4 shows associations of different parameters with mortality. Age was strongly associated with the risk of death. Workers aged $>40$ years at the time of registration had a 5.1-fold increased risk of death, compared with workers aged up to 40 years. These associations were therefore adjusted for age. In univariate analysis, mortality was significantly associated with BMI less than 1.751, abnormal PFT, silicosis,

Table 2: Overall results of follow up

\begin{tabular}{|c|c|c|c|}
\hline & $\begin{array}{l}\text { Workers working at } \\
\text { time of registration }\end{array}$ & $\begin{array}{l}\text { Workers who had discontinued } \\
\text { work at time of registration }\end{array}$ & Total \\
\hline Number registered in 1992-1994 & 416 & 42 & 458 \\
\hline Follow-up person years & 3571 & 360 & 3931 \\
\hline Lost to follow up $(n)$ & 9 & 1 & 10 \\
\hline Percent & $2.2 \%$ & $2.4 \%$ & $2.2 \%$ \\
\hline Workers working in quarries in $2002(n)$ & 321 & 13 & 334 \\
\hline Percent & $77.2 \%$ & $30.9 \%$ & $72.9 \%$ \\
\hline Discontinued job due to sickness $(n)$ & 58 & 7 & 65 \\
\hline Percent & $13.9 \%$ & $16.7 \%$ & $14.2 \%$ \\
\hline Died through July 2002, No. of deaths & 28 & 21 & 49 \\
\hline Percent & $6.8 \%$ & $51.2 \%$ & $10.9 \%$ \\
\hline Death rate per 1000 person years & 8.0 & 59.7 & 12.7 \\
\hline Average age at time of death of deceased (years) & $46.0 \pm 10.6$ & $59.5 \pm 10.7$ & $51 \pm 12.5$ \\
\hline Range & $29-64$ & $31-77$ & $29-77$ \\
\hline SMR (of all causes) & 1.38 & 2.54 & 1.72 \\
\hline $95 \% \mathrm{Cl}$ of $\mathrm{SMR}$ & $0.87-1.89$ & $1.45-3.62$ & $1.23-2.19$ \\
\hline
\end{tabular}

Table 3: Standardized mortality ratio according to results of spirometery

\begin{tabular}{|c|c|c|}
\hline Result of spirometery & No. of deaths (No. followed) & Standardized mortality ratio $(95 \% \mathrm{CI})$ \\
\hline Normal (neither obstruction nor restriction) & $1(130)$ & $0.54(-0.07-1.61)$ \\
\hline Obstruction without restriction & $10(101)$ & $1.32(0.63-2.02)$ \\
\hline Restriction without obstruction & $4(31)$ & $2.34(0.29-4.39)$ \\
\hline Obstruction with or without restriction & $18(135)$ & $1.75(1.09-2.41)$ \\
\hline Restriction with or without obstruction & $12(65)$ & $2.61(1.41-3.82)$ \\
\hline Restriction and obstruction (mixed) & $8(34)$ & $2.73(1.24-4.21)$ \\
\hline
\end{tabular}


Table 4: Hazard ratios for all cause mortality in relation to different factors (adjusted for age) in univariate analysis

\begin{tabular}{|c|c|c|c|c|c|}
\hline Characteristic (at time of registration) & No. of subjects & No. (\%) of deaths & Hazard ratio & $95 \% \mathrm{Cl}$ of hazard ratio & $P$-value \\
\hline \multicolumn{6}{|l|}{ Result of PFT } \\
\hline Normal PFT (N) & 134 & $3(2.2)$ & 1.0 & & \\
\hline Restriction without obstruction (R) & 36 & $5(13.9)$ & 6.00 & $4.79-7.52$ & $<0.001$ \\
\hline Mixed $(R+0)$ & 49 & $13(26.5)$ & 11.98 & $9.84-14.59$ & $<0.001$ \\
\hline \multicolumn{6}{|l|}{ C/0 Ch. dyspnoea } \\
\hline Absent & 246 & $10(4.1)$ & 1.0 & & \\
\hline Absent & 393 & $29(7.4)$ & 1.0 & & \\
\hline Present & 54 & $20(37.0)$ & 3.98 & $3.64-4.34$ & $<0.001$ \\
\hline \multicolumn{6}{|c|}{ Opacities suggestive of TB in X-ray chest } \\
\hline Absent & 367 & $27(7.4)$ & 1.0 & & \\
\hline Present & 80 & $22(27.5)$ & 3.36 & $3.08-3.67$ & $<0.001$ \\
\hline \multicolumn{6}{|l|}{ BMI } \\
\hline Duration $>15$ years & 185 & $36(19.5)$ & 3.33 & $3.01-3.69$ & $<0.001$ \\
\hline \multicolumn{6}{|l|}{ Opium } \\
\hline Nonaddict & 403 & $39(9.7)$ & 1.0 & & \\
\hline Opium-addict & 44 & $10(22.7)$ & 1.81 & $1.62-2.02$ & $<0.001$ \\
\hline \multicolumn{6}{|l|}{ H/O hemoptysis } \\
\hline Absent & 329 & $26(7.9)$ & 1.0 & & \\
\hline Present & 118 & $23(19.5)$ & 2.15 & $1.97-2.35$ & $<0.001$ \\
\hline \multicolumn{6}{|l|}{$\mathrm{C} / 0$ pain chest } \\
\hline Absent & 221 & $15(6.8)$ & 1.0 & & \\
\hline Present & 226 & $34(15.0)$ & 2.18 & $1.98-2.40$ & $<0.001$ \\
\hline \multicolumn{6}{|l|}{ Smoking habit* } \\
\hline Nonsmoker & 83 & $8(9.6)$ & 1.0 & & \\
\hline Smoker & 364 & $41(11.3)$ & 0.96 & $0.86-1.07$ & $0.47^{*}$ \\
\hline
\end{tabular}

* No significant association.

duration of working in sandstone quarries more than 15 years, opacities suggestive of TB in chest X-ray, opium addiction, history of hemoptysis in last 6 months, complain of chronic chest pain, and complain of chronic dyspnoea. In PFT, those who showed mixed abnormality (obstruction as well as restriction) had maximum risk of death (hazard ratio $=11.98,95 \%$ CI $9.84-14.59$ ). Smoking habit and use of alcohol did not show significant association with mortality. Crude opium is customarily offered with social sanction in villages of this region; as a result many adult males start regular use of opium and become opium addicts. Opium addiction was also found to be a significant predictor of all-cause mortality in univariate analysis (hazard ratio $=1.81,95 \%$ CI $1.62-2.02$ ).

In multivariate Cox proportional hazard model, abnormal PFT, silicosis, more than 15 years duration of working in sandstone quarries, complaints of chronic chest pain, complaints of chronic dyspnoea, BMI less than 1.75, and opium addiction all emerged as significant predictors of allcause mortality, while history of hemoptysis in last 6 months and opacities of TB in X-ray lost significance [Table 5].

\section{DISCUSSION}

The sandstone quarries in Jodhpur district are a major source of employment in the district. These are open quarries on surface of rocky land. The workers drill holes in rocks with chisel and big hammers, but in the last few years, drilling machines are being used in most of the quarries. After drilling holes in straight line in a rock they put some explosives in holes and blast them. This breaks the rocks into huge blocks, which are then cut into long slabs or stones. This stone cutting is done manually using huge hammers. In the process of quarrying, workers are exposed to high concentrations of silica rich respirable dust. Measures of prevention of silicosis are practically not adopted by them. Evaluating all-cause mortality for the study subjects in the follow-up period, we found significantly higher mortality than expected (SMR = 1.72, 95\% CI $1.23-2.19)$. The deaths were mainly attributed to chronic respiratory diseases by the relatives of the deceased. In the estimation of SMR, the groups of workers are compared with the national age specific death rates of the respective countries. This type of comparison is most often considered as an underestimation of the true risk, as 
Table 5: Multivariate Cox proportional hazard model for predictors of all cause mortality (hazard ratio adjusted for age)

\begin{tabular}{|c|c|c|c|}
\hline Characteristic (at time of registration) & Hazard ratio & $95 \% \mathrm{Cl}$ of hazard ratio & $\boldsymbol{P}$-value \\
\hline \multicolumn{4}{|l|}{ Result of PFT } \\
\hline Normal PFT (N) & 1.0 & & \\
\hline Restriction without obstruction(R) & 13.95 & $9.14-21.29$ & $<0.001$ \\
\hline Mixed $(\mathrm{R}+0)$ & 5.92 & $4.20-8.36$ & $<0.001$ \\
\hline \multicolumn{4}{|l|}{ Opacities suggestive of silicosis in X-ray chest } \\
\hline Absent & 1.0 & & \\
\hline Duration upto15 years & 1.0 & & \\
\hline Duration $>15$ years & 7.29 & $5.19-10.24$ & $<0.001$ \\
\hline \multicolumn{4}{|l|}{ C/O Ch. dyspnoea } \\
\hline Absent & 1.0 & & \\
\hline Present & 6.48 & $4.70-8.95$ & $<0.001$ \\
\hline \multicolumn{4}{|l|}{ BMI } \\
\hline \multicolumn{4}{|l|}{ Opium } \\
\hline Nonaddict & 1.0 & & \\
\hline Opium-addict & 1.39 & $1.06-1.82$ & 0.01 \\
\hline \multicolumn{4}{|l|}{ H/O hemoptysis * } \\
\hline Absent & 1.0 & & \\
\hline Present & 0.98 & $0.81-1.17$ & $0.80^{*}$ \\
\hline \multicolumn{4}{|c|}{ Opacities suggestive of TB in X-ray chest* } \\
\hline Absent & 1.0 & & \\
\hline Present & 0.87 & $0.69-1.09$ & $0.22 *$ \\
\hline
\end{tabular}

* Not significant predictor of mortality.

the general population includes sick and disabled people, unable to work. This underestimation is well known as the healthy worker effect. ${ }^{[6]}$ To avoid this underestimation, the present follow-up study included ex-workers equal to $10 \%$ of active workers. This was done because most workers are likely to discontinue their job some time before their death, who are likely to be excluded from the follow-up study, if only active workers are followed up. Average age at the time of death was only $46.0 \pm 10.6$ years in those deceased who were actively working in 1992-1994, which is very low. Even this was arrived at when a group of workers who had already survived average 12.9 years duration of working in quarries were followed. If a cohort of those newly starting the job is followed, the average age at time of death of deceased could be even less than this.

The average age at time of registration was higher in exworkers and therefore their average age at the time of death was also higher. Average age at the time of registration of active workers was 31.9 years and the average duration of their working was 12.9 years; it suggests that they started working in quarries around the age of 19 years, while average age at the time of registration of ex-workers was 51.1 years and their average duration of working was 22.2 years, suggesting that they had started working in quarries around
29 years. These facts indicate that those who start working at late age survive longer.

Abnormal PFT, longer duration ( $>15$ years) of working in sandstone quarries, silicosis, complain of chronic dyspnoea, complain of chronic chest pain, BMI less than 1.75, and opium addiction emerged as significant predictors of all-cause mortality in these workers. Among abnormalities in PFT, restriction was the strongest predictor (hazard ratio $=13.95_{i}$ 95\% CI 9.14 - 21.29). Exposure to crystalline silica is known to be associated with a high risk of silicosis, lung cancer, COPD and pulmonary tuberculosis. ${ }^{[7]}$ Secondly, more than $80 \%$ of these workers were smokers, which increase risk of COPD and lung cancer. Highest hazard ratio for restriction in PFT is probably indicator of the important role of silicosis in mortality as silicosis is known to cause restriction and COPD is known to show obstruction in PFT, whereas tuberculosis and lung cancers also bring abnormality in PFT. The lower BMI seems to indicate the severity of the silicosis, chronic obstructive pulmonary disease (COPD), lung cancer, or tuberculosis resulting in premature death. Longer duration of exposure is required for the development of these diseases except for tuberculosis, susceptibility to which is known to be increased by exposure to silica rich dust. Chronic dyspnoea is a common symptom in silicosis and COPD. The strong 
predictors of mortality in multivariate model probably indicate that these diseases might be the underlying causes of higher mortality. In the absence of availability of the certified cause of death in death certificates, in resource poor settings, the results of present study, indicate significantly higher mortality in these sandstone quarry workers, average age at death among whom is only $46.0 \pm 10.6$ years, and most deceased suffered from chronic respiratory diseases. The study thus underlines the need for adopting measures of prevention of generation of fine dust and prevention of exposure of workers to such dust in these quarries. Dry mechanical drilling is an important source of generation of fine dust in environment of quarries. The process of dry mechanical drilling should be replaced with the wet drilling process, feasibility of which has been shown by us in another study sponsored by the World Health Organization. ${ }^{[8]}$ The workers should not make their huts near their working sites, rather they should prefer to live at least $1-2 \mathrm{~km}$ away from the mining area and this would restrict their exposure to dusty air for only $8 \mathrm{~h}$ instead of $24 \mathrm{~h}$ a day. They can also use appropriate facemasks, while working.

\section{REFERENCES}

1. Mathur ML. Silicosis among sand stone quarry workers of a desert district Jodhpur. Ann Nat Acad Med Sci 1996;32:113-8.

2. Guidelines for the use of ILO International classification of Radiographs of pneumoconioses. Occupational Safety and Health Series 22 Rev. Ed. International Labour Office: Geneva; 1980. p. 1-30.

3. Purohit SD, Srivastava AB, Gupta PR, Gupta SD, Mathur BB, Gupta ML. Spirometeric norms in Healthy adults of Rajasthan. Lung India 1989;1:9-14.

4. Registrar General, India. Compendium of India's fertility and mortality indicators 1971 - 1997 based on The Sample Registration System (SRS). New Delhi Registrar General: India; 1999.

5. Kahn HA, Sempos CT. Statistical Methods in Epidemiology. Oxford University Press: Oxford, England; 1989. p. 97-102.

6. McMichael AJ. Standardized mortality ratios and the "healthy worker effect": scratching beneath the surface. J Occup Med 1976;18:165-8.

7. Calvert GM, Rice FL, Boiano JM, Sheehy JW, Sanderson WT. Occupational silica exposure and risk of various diseases: an analysis using death certificates from 27 states of the United States. Occup Environ Med 2003;60:122-9.

8. Desert Medicine Research Centre. Feasibility Study of Measures for Prevention of Silicosis in Sandstone Quarry workers of Western Rajasthan. Technical Report. DMRC: Jodhpur; 2002. p. 5-25.

\title{
ANNOUNCEMENT
}

\section{The 13th International Congress on Occupational Health Services}

\author{
1st - 3rd December, 2005 in Utsunomiya City, Japan
}

The proceedings will be published from Elsevier B. V. as one of the International Congress Series.

Selected papers will be published from a special edition of "Industrial Health." The deadline of abstract submission is the end of this month, August 31, 2005. For more information on abstract submission and registration, please visit the following Congress website at:

http://www.dokkyomed.ac.jp/dep-m/pub/ohs2005.html

\author{
Takashi MUTO \\ Chair
}

Department of Public Health, Dokkyo University School of Medicine

Kita-kobayashi 880, Mibu, Tochigi 321-0293 JAPAN

Tel: +81282 872133 Fax: +81282862935

E-mail: ohs2005@dokkyomed.ac.jp 